\title{
COMMENT
}

\section{"Holistic Promotion of Scholarship and Advancement" APS racism series: at the intersection of equity, science, and social justice}

\author{
Steven H. Abman (D) \\ Pediatric Research (2020) 88:694-695; https://doi.org/10.1038/s41390-020-01131-9
}

\begin{abstract}
As academic pediatricians, unique opportunities exist within departments, medical centers, and universities to renew institutional values and commitments, forge new policies, and translate changes in education, training, research, and advocacy that will have sustained impact in combating the adverse effects of racism and inequities on the health of our children and their families. ${ }^{1-6}$ Racism, inequities in diversity and inclusion, and social injustice have had horrific effects throughout all aspects of society, but especially regarding many short- and long-term health issues, ranging across the full gamut of life course, from perinatal and birth events to early death and higher rates of many morbidities in adulthood. ${ }^{7-11}$ Along with personal and individual commitments of well-intentioned physicians and health providers throughout medicine, successful change must thoroughly involve academic institutions, medical societies, and health departments, which have particular responsibilities to commit to disrupting this cycle through the development and application of various strategies to address these issues at multiple levels. $^{12-18}$ The academic community seeks to address racism, inequity, lack of diversity, and issues with inclusion that impact child health, but must first recognize and act on its own issues of implicit bias. Every academic institution and related national and international organizations must first address and develop into systems that embody the highest values of antiracism, equity, and inclusion. Such efforts require self-examination and greater awareness of the many manifestations of institutional bias and addressing these issues with honesty, transparency, and a great sense of purpose within each organization.
\end{abstract}

Overall, there is a clear challenge to our medical institutions to address these issues, especially within pediatric medicine, even beyond the traditional borders of childhood disease, through the promotion of effective strategies to enhance research, education, training, and advocacy throughout the educational and professional pipeline. This pipeline involves all stages of career development, from early school-age exposures to encourage the sense of possibility for having careers in medicine and related scientific fields, to provide guidance throughout the educational system, and finally, to support the retention and promotion of underrepresented faculty in diverse leadership roles throughout academic medicine. The overall mission of academic centers must be to more fully develop and implement innovative strategies to recognize and remove unconscious or implicit bias while aiming for full inclusion and engagement of individuals throughout all aspects of clinical care, research, education, and training in our medical centers.
Providing a more diverse workforce is of the utmost importance for achieving greater outcomes in child health, and it is very clear that diversity further improves and benefits achievement within each team and makes each organization better as well. In addition to patient care and management, focused efforts are needed to improve the education, training, and career support of all medical professionals, ranging from students, residents, fellows, and faculty from all race and ethnic backgrounds. Steps to achieve workforce diversity must begin with more successful approaches to strengthening the early pipeline. Supporting educational opportunities and developing ties between academic centers with local and national programs for young students will provide greater exposure of under-represented youth to science and provide a greater sense of feasibility and early commitment to a career in medicine and health-related sciences. Developing novel educational and research programs for high school students to increase interactions and opportunities at each academic medical center will provide foundational experiences to encourage medical careers. The importance of key role models who provide the mentorship, advice, and support even at this early stage cannot be over-emphasized. As such, identifying key role models and educators from the entire academic community that include faculty from diverse backgrounds is important, as this is a shared responsibility, which is not exclusive to under-represented faculty alone and will help to generalize strategies and teaching across races and ethnicities and directly speaks to shared goals throughout the institution.

Promoting the application of novel curricula design in medical student education to increase awareness of social factors and improve the quality of care for our diverse patients and their families is essential. Medical education is undergoing reevaluation with anticipated revision of its curriculum to better integrate basic science with social determinants to better understand disease and outcomes as well as hospital care with a greater sense of community issues. Such experiences will provide an earlier and more consistent understanding of how social determinants affect health and disease beyond the structure of training programs in the past and an essential foundation throughout each student's career, regardless of subsequent specialty or practice setting. Such exposures should better inform practitioners of the future to understand and deliver more equitable and effective health care. Commitment to removing bias from the selection process for residency and fellowship training is critical to further support these goals.

\footnotetext{
${ }^{1}$ Pediatric Heart Lung Center, University of Colorado Anschutz School of Medicine and Children's Hospital Colorado, Aurora, CO 80045, USA
} Correspondence: Steven H. Abman (abman@cuanschutz.edu)

Received: 22 July 2020 Accepted: 28 July 2020

Published online: 11 September 2020 
It is of further importance to explore research programs that strongly engage under-represented students in medicine and research among its investigative team members to enhance their careers as academic leaders. Despite many efforts and ongoing emphasis by the $\mathrm{NIH}$, diversity among the $\mathrm{NIH}$-funded biomedical workforce remains low. New approaches for achieving sustainable academic success in under-represented faculty have been recently described, including a novel program that promotes development of research skills and career advancement as exemplified by the Research in Academic Pediatrics Initiative on Diversity (RAPID) program. ${ }^{15}$ In addition, the implementation of programs to increase "culturally aware" mentorship training with inclusion of both mentors and mentees provides another example of a successful strategy towards improving diversity in our academic centers. ${ }^{16}$ We should further foster and help fellows and faculty apply for $\mathrm{NIH}$ research supplements that promote diversity, pay special attention to junior URM faculty, and help guide them through milestones to become successful senior faculty and leaders of academic programs, departments, and health care institutions.

As disparities in leadership at academic medical centers persist, better approaches are needed to increase opportunities and promote under-represented faculty to more leadership roles throughout our institutions. Academic medicine is enriched by leaders from a diversity of racial, gender, and ethnic backgrounds, and applying primary interests in specific academic themes, issues, and skill sets, ranging from advocacy to broad research areas, including patient-, laboratory-', and population-based sciences. One should assume that all students are potential candidates for leaders in academic medicine at multiple levels, from clinical care, research, education, hospital management and administration, and university wide leadership.

Thus, academic medicine must have a vigorous response to meet the long-neglected challenges to aggressively address racism, implicit bias, and social injustice as determinants of child health. Promoting successful careers to address these challenges require multipronged strategies at all stages of the academic pipeline, but especially to develop the new leadership that is required to successfully achieve goals of equity and inclusion. As pediatricians and leaders of academic medicine, medical schools, universities, and related societies have many opportunities to address critical responsibilities to drive progress forward for strengthening a diverse workforce to meet these challenges of equity, diversity, and inclusion, and ultimately improve the health outcomes of our children and their families.

\section{ACKNOWLEDGEMENTS}

This paper is part of a series of manuscripts organized by Dr. Josepth Wright and Leslie Walker-Harding for the Public Policy Committee.

\section{ADDITIONAL INFORMATION}

Competing interests: The author declares no competing interests.

Publisher's note Springer Nature remains neutral with regard to jurisdictional claims in published maps and institutional affiliations.

\section{REFERENCES}

1. Trent, M. et al. Section on adolescent health; council on community pediatrics; committee on adolescence. The impact of racism on child and adolescent health Pediatrics 144, e20191765 (2019).

2. Williams, D. R. \& Cooper, L. A. Reducing racial inequities in health: using what we already know to take action. Int. J. Environ. Res. Public Health 16, 606-631 (2020).

3. Owe, W. R., Carmona, R. \& Pomeroy C. Failing another national stress test on health disparities. JAMA https://doi.org/10.1001/jama.2020.6547 (2020).

4. Dreyer, B. P. et al. The death of George Floyd: bending the arc of history towards justice for generations of children. Pediatrics https://doi.org/10.1542/peds.2020009639 (2020).

5. Hardeman, R. R., Medina, E. M. \& Kozhimannil, K. E. Structural racism and supporting black lives-the role of health professionals. N. Engl. J. Med. 375, 2113-2115 (2016).

6. Hardeman, R. R., Medina, E. M. \& Boyd, R. W. Stolen breaths. N. Engl. J. Med. https://doi.org/10.1056/NEJMp2021072 (2020).

7. Yancy, C. W. COVID-19 and African Americans. JAMA https://doi.org/10.1001/jama (2020).

8. Siddiqi, A., Jones, M. K., Bruce, D. J. \& Erwin, P. C. Do racial inequities in infant mortality correspond to variations in societal conditions? A study of state-level income inequality in the U.S., 1992-2007. Soc. Sci. Med. 164, 49-58 (2016).

9. MacDorman, M. F. et al. Recent increases in the U.S. maternal mortality rate: disentangling trends from measurement issues. Obstet. Gynecol. 128, 447-455 (2016).

10. Minehart, R. D., Jackson, J. \& Daly, J. Racial differences in pregnancy-related morbidity and mortality. Anesthesiol. Clin. 38, 279-296 (2020).

11. Price-Haywood, E. G., Burton, J., Fort, D. \& Seoane, L. Hospitalization and mortality among black and white patients with COVID-19. N. Engl. J. Med. 382, 2534-43. (2020).

12. Carethers, J. M. et al. The imperative to invest in science has never been greater. J. Clin. Invest. 124, 3680-3681 (2014).

13. Nolen, L. How medical education is missing the bull's eye. N. Engl. J. Med. 328, 2489-91. (2020).

14. Carethers, J. M. Facilitating minority medical education, research and faculty. Dig. Dis. Sci. 61, 1436-1439 (2016).

15. Flores, G. et al. Keys to academic success for under-represented minority young investigators: recommendations for the Resaerch in Academic Pediatrics Initiative on Diversity (RAPID) National Advisory Committee. Int. J. Equity Health $\mathbf{1 8}$ 93-107. (2019).

16. Byars-Winston, A. et al. Pilot study of an intervention to increase cultural awareness in research mentoring: implications for diversifying the scientific workplace. J. Cin. Transl. Sci. 2, 86-94 (2018).

17. Ansell, D. A. \& McDonald, E. K. Bias, black lives, and academic medicine. N. Engl. J. Med. 372, 1087-1089 (2015).

18. Bassett, M. T. \#BlackLivesMatter-a challenge to the medical and public health communities. N. Engl. J. Med. 372, 1085-1087 (2015). 